\title{
Effects of undergraduate medical students' individual attributes on perceptions of encounters with positive and negative role models
}

\author{
Masami Tagawa
}

\begin{abstract}
Background: The use of role models (RMs) is a successful educational strategy. In formal training and other settings during undergraduate education, students have the opportunity to recognize numerous traits and behaviors of their RMs, such as teaching skills, professionalism in the clinical setting, and personal qualities. Encountering both positive and negative RMs allows medical students to learn a variety of professional norms and values. This learning process is likely influenced by a student's developmental status, which itself is related to that student's personal attributes and experiences. The purpose of this study was to examine graduating medical students' perceptions of their RM encounters and their learning processes, and how these perceptions and processes are affected by their own personal attributes.
\end{abstract}

Methods: Sixth-year medical students were asked to complete questionnaires in 2013 and 2014 regarding encounters with positive or negative RMs, in terms of patient relationships, clinical expertise, teaching ability, and other factors, during clinical training and other situations. Associations between gender, age, admission status, and recognition of self-achievement and joy of learning in relation to RM encounters were then analyzed.

Results: Among 115 students (75 males, 40 females) who completed the questionnaires, 113 (98.3 \%) and 85 (73.9\%) reported encountering positive and negative RMs, respectively. The majority of students reported encountering both positive and negative RMs in terms of relationships with patients, humanity, and teaching ability, and fewer negative RMs in terms of clinical expertise and contributions to the community. Older students, males, and those who had passed an entrance examination for bachelors reported encountering more negative RMs in terms of relationships with patients, humanity, and teaching ability than younger students, females, and general admission students. These results suggested an association between positive and negative RM encounters and recognition of self-achievement and joy of learning in formal clinical training.

Conclusions: Most medical students encountered both positive and negative RMs during undergraduate medical education. These findings suggest that encounters with not only positive, but also negative RMs might facilitate student learning. Therefore, personal development appears to affect student perception of RMs.

Keywords: Role model, Gender, Professional development, Formal curriculum 


\section{Background}

Role modeling is an essential and powerful educational strategy that allows medical students to obtain the attributes and values of, and develop identities as, medical doctors [1, 2]. Medical students learn from role models (RMs) by example; however, not all RMs exhibit positive professional behavior. Previous studies have investigated the behavior of positive RMs through qualitative or quantitative analysis of students [3, 4], residents [5], or clinical faculty and staff $[6,7]$. Passi et al. reviewed 39 studies and categorized the attributes of positive RMs into the following three domains: clinical attributes (an excellent level of clinical knowledge and skills, patientcentered approach, humanistic behavior); teaching skills (establishing rapport with learners, creating a positive and supportive educational environment, developing specific teaching methods, being committed to the growth of the learners, teaching responsibility, providing students with ample patient interaction); and personal qualities (effective interpersonal skills, a positive outlook, integrity, good leadership skills, a commitment to excellence, dedication, honesty, politeness, enthusiasm, inspiring students) [8]. In addition, Wright et al. described an excellent RM as a physician who enjoys teaching in-house staff, commits substantial effort to teaching, and emphasizes doctor-patient relationships and psychosocial aspects of patient care in their teaching [6]. Professionalism is emphasized in medical education; therefore, other studies have investigated instances in which a lack of professionalism or ethical dilemmas were encountered by medical students [9-12] and residents [13]. Responsibility for community has also been identified as another aspect of professionalism [14].

Students observe RMs both consciously and unconsciously, and as a result, typically lose some degree of their ethical behavior or humanism $[9,15]$. The development of values and the ability to learn is dependent on formal training and informal and hidden curriculum in clinical courses [16-18]. Shuval and Adler analyzed the modeling processes of medical students based on socialization theory and identified the following three patterns of value formation: active identification, in which students' attitudes begin to resemble those of their RMs over time; active rejection, in which students' attitudes become more dissimilar to those of their RMs over time; and inactive orientation, a pattern of relative passivity compared to the first two, in which students display no change in their attitude [19]. To understand the influence of RMs on value formation in medical students, individual student experiences with RMs during undergraduate medical education need to be investigated, as well as whether students witness their RMs conducting ideal or unprofessional behaviors, and which student factors, aspects of RM behaviors, and learning contexts may have affected student learning and perceptions of RMs.

The purpose of this study was to examine graduating medical students' perceptions of their RM encounters and how their personal attributes affected their perceptions. Student encounters with their RMs are also examined in relation to their recognition of self-achievement.

\section{Methods}

This cross-sectional study was approved by and conducted according to the guidelines and requirements of the ethics committee of the Graduate School of Medical and Dental Sciences, Kagoshima University. Among all sixth-year medical students at Kagoshima University during 2013 and 2014, written informed consent was obtained from a total of 157 who agreed to participate.

\section{Development of the questionnaire}

A self-administered questionnaire regarding medical students' RM encounters and recognition of self-achievement and joy of learning was developed and subsequently integrated into a questionnaire for undergraduate education.

The first part of questionnaire asked students to rate their frequency of recognition of self-achievement and joy of learning in formal clinical training courses on 6-point Likert scale as follows: 1, none; 2, 1-2 times; 3, 3-4 times; 4, 5-6 times; 5, 7-9 times; and 6, 10 times or more.

The second part of questionnaire was composed of items on whether they themselves had observed good RM behavior (positive RMs) or bad RM behavior that made them think "I will never behave like that" (negative RMs) (Additional file 1). To clarify various aspects of behaviors, actions, and attributes and make student responses more concrete, the following six categories of behaviors and attributes were selected based on previous research on RMs [6, 8-14]: a) relationship with patients; b) clinical expertise; c) humanity and personal attributes; d) lifestyle; e) teaching students and health care professionals; and f) contributions to the community. Students provided "yes/no" responses based on whether they had encountered RMs in each category during formal clinical training courses or other situations.

The questionnaires were distributed in envelopes to sixth-year students in September 2013 and July 2014 who had completed all undergraduate medical courses and had previously consented to participate in this study. Students were asked to return completed questionnaires to a drop box in the student lounge. The chi-square test, $\mathrm{t}$ test, nonparametric Kruskal-Wallis test [20], and logistic regression were used to analyze student responses (SPSS version 23; IBM, New York, NY). 


\section{Results}

\section{Demographic characteristics of the participants}

A total of 115 sixth-year Japanese medical students (75 males, 40 females; 2013, 44 students; 2014, 71 students) responded to both parts of the questionnaire. The response rate was $73.2 \%$ (males, $70.8 \%$, females, $82.0 \%$ ) among the 157 students who consented to participate in this study, and $53.7 \%$ (51.0\% male, $59.7 \%$ female) among the total of 214 students who were targeted. The mean age of the respondents was 26.4 years (age range, 23-51 years; median, 25 years) (Table 1$)$. Thirteen participants (7 males, 6 females) who had passed an entrance examination for bachelors were admitted to the middle of the second year of the medical program. The mean age of these students (33.9 years) was 8.4 years higher than that of students who had entered into medical school through general admission.

\section{RM encounters in formal clinical training courses and other situations}

All 115 students (100\%) indicated that they had encountered RMs in formal clinical training courses, and 93 (80.9 \%) had encountered RMs in other situations (Fig. 1). A total of 113 (98.3\%) and 85 (73.9\%) students reported encountering positive and negative RMs, respectively, with $112(97.4 \%)$ and 81 (70.4\%) encountering positive and negative RMs in formal clinical training courses.

Regarding the experiences of each student with RMs, 83 students (72.2\%; 56 males [74.4\%], 27 females [67.5\%]) encountered both positive and negative RMs, 30 (26.1 \%; 17 males [22.7 \%], 13 females [32.5 \%]) encountered only positive RMs, and two male students (1.7\%) encountered only negative RMs during undergraduate medical education (Fig. 1b). Students' RM

Table 1 Demographic characteristics of the participants

\begin{tabular}{|c|c|c|c|c|c|c|}
\hline & \multirow[b]{2}{*}{$n$} & \multicolumn{5}{|c|}{ Age (years) } \\
\hline & & Mean & SD & Min & Max & Median \\
\hline Total & 115 & 26.4 & 4.33 & 23 & 51 & 25 \\
\hline Male & 75 & 26.7 & 4.46 & 23 & 51 & 25 \\
\hline Female & 40 & 26.0 & 4.09 & 23 & 39 & 25 \\
\hline General $^{a}$ & 102 & 25.5 & 3.42 & 23 & 51 & 25 \\
\hline Male & 68 & 26.0 & 4.05 & 23 & 51 & 25 \\
\hline Female & 34 & 24.5 & 0.96 & 23 & 27 & 24 \\
\hline Bachelor $^{b}$ & 13 & 33.9 & 3.51 & 29 & 39 & 33 \\
\hline Male & 7 & 33.1 & 2.85 & 31 & 38 & 31 \\
\hline Female & 6 & 34.7 & 4.27 & 29 & 39 & 35 \\
\hline
\end{tabular}

${ }^{a}$ Admitted to the first year of the medical program as high school graduates ${ }^{b}$ Graduated from other university and admitted to the 2 nd year of the medical program encounters by age and admission group are shown in Fig. 1. More male and older students encountered negative RMs, but this difference was not significant. Overall, no significant differences were found in positive and negative RM encounters between gender, age, or admission groups.

\section{Aspects of RM behavior and attributes}

RM encounters were analyzed according to six RM categories. As shown in Table 2, the number of students who encountered positive RMs in formal clinical training courses ranged from 84 (73.0 \%, "lifestyle") to 104 (90.4 \%, "teaching"), and the number of students who encountered negative RMs ranged from 22 (19.1\%, "community contribution") to 73 (63.5\%, "relationship with patients"). Students reported encountering both positive and negative RMs in terms of "relationship with patients", "humanity", and "teaching", and fewer negative RMs in terms of "lifestyle". In other informal situations, the numbers of students who encountered positive RMs ranged from 61 (53.0\%, "clinical expertise", "teaching") to $69(60.0 \%$, "relationship with patients"), and the numbers of students who encountered negative RMs ranged from 14 (12.2\%, "contributions to the community") to 38 (33.0\%, "relationship with patients").

Influence of student characteristics on perceptions of RMs Specific RM encounters (category, context, positive or negative) were also analyzed in terms of gender, age, and admission status (Table 2), as well as individual student experiences (positive RMs only, positive and negative RMs, negative RMs only, and no RM encounters) (Table 3).

Male or older students reported encountering negative RMs in all categories in both contexts more frequently than female or younger students (Table 2). Bachelor admission students reported encountering fewer positive RMs in all categories in both contexts, and more negative RMs in terms of "humanity" and "teaching" in other informal situations compared with general admission students.

To examine the effects of multiple factors on RM encounters, logistic regression was applied using gender, age, and admission group as independent variables. Gender was a significant factor in predicting negative RMs in terms of "relationship with patients" (percentage of correct predictions, $67.8 \% ; p<0.01$ ), and age was a significant factor in predicting negative RMs in terms of "clinical expertise" $(83.5 \% ; p<0.05)$, "teaching" $(80.0 \% ; p<0.01)$, and "contributions to the community" (87.8\%; $p<0.05)$ in informal situations.

Some tendencies were found regarding individual student experiences of RM encounters (Table 3). For example, students who encountered negative RMs but no positive RMs tended to be older, male, and bachelor admission students than students who encountered 
a Context of RM encounters

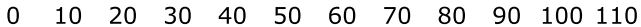

Formal clinical courses Other situations

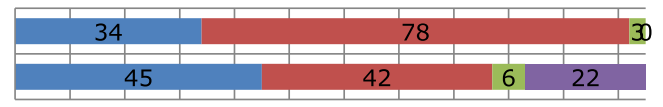

P

$\begin{array}{lll}\mathrm{P}+\mathrm{N} & \mathrm{N} & \text { None }\end{array}$

b Students' attributes

1) Gender

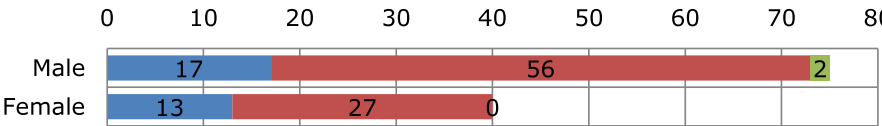

$\square \mathrm{P} \square \mathrm{P}+\mathrm{N}$

2) Age (years)

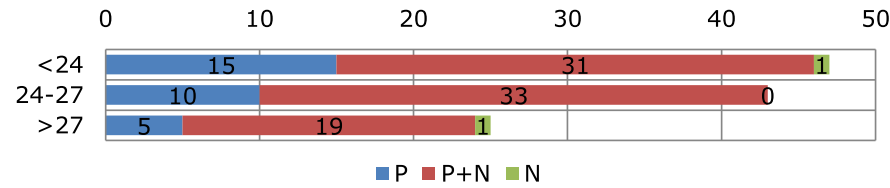

3) Admission group

\begin{tabular}{|c|c|c|c|c|c|c|c|c|c|c|}
\hline 0 & 10 & 20 & 30 & 40 & 50 & 60 & 70 & 80 & 90 & 100 \\
\hline General & 2 & & & & & & & & & 1 \\
\hline Bachelor & 81 & & & & & & & & & \\
\hline
\end{tabular}

$\square \mathrm{P} \square \mathrm{P}+\mathrm{N} \square \mathrm{N}$

Fig. 1 Number of students who encountered role models (RMs) during undergraduate medical education, based on the contexts (a) and students' attibutes (b). P: students who encountered only positive RMs; P + N: students who encountered both positive and negative RMs; N: students who encountered only negative RMs; None: students who did not encounter any RMs

positive RMs; however, no significant differences in age were detected by the $t$ test.

\section{Student's recognition of achievement and RM encounters in formal clinical training courses}

The association between students' "recognition of selfachievement and joy of learning" and their experiences regarding RM encounters in each category is shown in Fig. 2.

The only significantly different frequency distribution for self-achievement and joy of learning among RM encounter groups was for "teaching"; this was likely the result of the small sample size in this study. However, among all RM categories, students who encountered positive RMs (positive RMs only, positive and negative RMs) recognized self-achievement and joy of learning more frequently than those who did not encounter any positive RMs (negative RM only, no RM encounters) (difference of means for "relationship with patients" and "lifestyle", $p<0.05)$. In addition, students who encountered both positive and negative RMs recognized selfachievement and joy of learning more frequently than those who encountered positive RMs only (difference in means for "teaching", $p<0.05)$.

\section{Discussion}

This study attempted to examine how graduating medical students view their previous encounters with RMs based on their values and norms and a contextual understanding, as well as which behaviors and attributes of their instructors or others encouraged students to perceive them as RMs in formal clinical training or other situations.

Although the vast majority of students reported encountering RMs who exhibited desirable actions, behaviors, or personal attributes, $74 \%$ also reported encountering negative RMs during their undergraduate medical education. Wright reported that $88 \%$ of the medical residents at McGill University in Canada had a personal RM [5], and each student nominated an average of 3.7 physicians as their personal RM [3]. Previous reports from the 1990 s revealed that $90 \%$ of medical students [10] and $92.5 \%$ of residents [13] in the US either observed or experienced unethical or unprofessional conduct among their colleagues and superiors during training. In a study by Reddy et al., over $80 \%$ of students reported receiving insufficient feedback from faculty or residents, which was recognized as unprofessional behavior [12]. In this study, a smaller percentage of students reported encountering negative RMs compared 
Table 2 Numbers and attributes of students who encountered role models (RMs) by category, context, and type

\begin{tabular}{|c|c|c|c|c|c|c|c|c|c|c|c|c|c|c|c|c|c|}
\hline \multicolumn{3}{|l|}{ RMs } & \multicolumn{15}{|c|}{ Students who encountered RMs } \\
\hline \multirow{4}{*}{$\begin{array}{l}\text { Category of behaviors } \\
\& \text { attributes }\end{array}$} & \multirow{4}{*}{$\begin{array}{l}\text { Context of } \\
\text { encounter }\end{array}$} & \multirow{4}{*}{$\begin{array}{l}\text { Type } \\
\text { Positive/ } \\
\text { Negative }\end{array}$} & \multirow[t]{3}{*}{ Total } & \multicolumn{4}{|c|}{ Gender } & \multicolumn{6}{|c|}{ Age } & \multicolumn{4}{|c|}{ Admission } \\
\hline & & & & \multicolumn{2}{|c|}{ Male } & \multicolumn{2}{|c|}{ Female } & \multicolumn{2}{|c|}{$<24$} & \multicolumn{2}{|c|}{$24-27$} & \multicolumn{2}{|c|}{$>27$} & \multicolumn{2}{|c|}{ General } & \multicolumn{2}{|c|}{ Bachelor } \\
\hline & & & & $n$ & $\%$ & $n$ & $\%$ & $n$ & $\%$ & $n$ & $\%$ & $n$ & $\%$ & $n$ & $\%$ & $n$ & $\%$ \\
\hline & & & 115 & 75 & $100 \%$ & 40 & $100 \%$ & 47 & $100 \%$ & 43 & $100 \%$ & 25 & $100 \%$ & 102 & $100 \%$ & 13 & $100 \%$ \\
\hline \multirow{4}{*}{$\begin{array}{l}\text { a. Relationship with } \\
\text { patients }\end{array}$} & \multirow[t]{2}{*}{ Formal } & Positive & 102 & 66 & $88.0 \%$ & 36 & $90.0 \%$ & 44 & $93.6 \%$ & 38 & $88.4 \%$ & 20 & $80.0 \%$ & 93 & $91.2 \%$ & 9 & $69.2 \%$ \\
\hline & & Negative & 73 & 50 & $66.7 \%$ & 23 & $57.5 \%$ & 26 & $55.3 \%$ & 29 & $67.4 \%$ & 18 & $72.0 \%$ & 65 & $63.7 \%$ & 8 & $61.5 \%$ \\
\hline & \multirow[t]{2}{*}{ Others } & Positive & 69 & 45 & $60.0 \%$ & 24 & $60.0 \%$ & 26 & $55.3 \%$ & 25 & $58.1 \%$ & 18 & $72.0 \%$ & 62 & $60.8 \%$ & 7 & $53.8 \%$ \\
\hline & & Negative & 38 & 32 & $42.7 \%$ & 6 & $15.0 \%$ & 12 & $25.5 \%$ & 14 & $32.6 \%$ & 12 & $48.0 \%$ & 32 & $31.4 \%$ & 6 & $46.2 \%$ \\
\hline \multirow[t]{4}{*}{ b. Clinical expertise } & \multirow[t]{2}{*}{ Formal } & Positive & 103 & 68 & $90.7 \%$ & 35 & $87.5 \%$ & 41 & $87.2 \%$ & 40 & $93.0 \%$ & 22 & $88.0 \%$ & 92 & $90.2 \%$ & 11 & $84.6 \%$ \\
\hline & & Negative & 27 & 18 & $24.0 \%$ & 9 & $22.5 \%$ & 10 & $21.3 \%$ & 10 & $23.3 \%$ & 7 & $28.0 \%$ & 25 & $24.5 \%$ & 2 & $15.4 \%$ \\
\hline & \multirow[t]{2}{*}{ Others } & Positive & 61 & 44 & $58.7 \%$ & 17 & $42.5 \%$ & 25 & $53.2 \%$ & 22 & $51.2 \%$ & 14 & $56.0 \%$ & 56 & $54.9 \%$ & 5 & $38.5 \%$ \\
\hline & & Negative & 19 & 16 & $21.3 \%$ & 3 & $7.5 \%$ & 4 & $8.5 \%$ & 7 & $16.3 \%$ & 8 & $32.0 \%$ & 17 & $16.7 \%$ & 2 & $15.4 \%$ \\
\hline \multirow{4}{*}{$\begin{array}{l}\text { c. Humanity, } \\
\text { personal attributes }\end{array}$} & \multirow[t]{2}{*}{ Formal } & Positive & 100 & 64 & $85.3 \%$ & 36 & $90.0 \%$ & 42 & $89.4 \%$ & 39 & $90.7 \%$ & 19 & $76.0 \%$ & 92 & $90.2 \%$ & 8 & $61.5 \%$ \\
\hline & & Negative & 65 & 45 & $60.0 \%$ & 20 & $50.0 \%$ & 23 & $48.9 \%$ & 23 & $53.5 \%$ & 19 & $76.0 \%$ & 57 & $55.9 \%$ & 8 & $61.5 \%$ \\
\hline & \multirow[t]{2}{*}{ Others } & Positive & 66 & 43 & $57.3 \%$ & 23 & $57.5 \%$ & 25 & $53.2 \%$ & 27 & $62.8 \%$ & 14 & $56.0 \%$ & 60 & $58.8 \%$ & 6 & $46.2 \%$ \\
\hline & & Negative & 30 & 23 & $30.7 \%$ & 7 & $17.5 \%$ & 8 & $17.0 \%$ & 11 & $25.6 \%$ & 11 & $44.0 \%$ & 24 & $23.5 \%$ & 6 & $46.2 \%$ \\
\hline \multirow[t]{4}{*}{ d. Lifestyle } & Formal & Positive & 84 & 58 & $77.3 \%$ & 26 & $65.0 \%$ & 36 & $76.6 \%$ & 31 & $72.1 \%$ & 17 & $68.0 \%$ & 75 & $73.5 \%$ & 9 & $69.2 \%$ \\
\hline & & Negative & 36 & 26 & $34.7 \%$ & 10 & $25.0 \%$ & 12 & $25.5 \%$ & 15 & $34.9 \%$ & 9 & $36.0 \%$ & 32 & $31.4 \%$ & 4 & $30.8 \%$ \\
\hline & Others & Positive & 64 & 43 & $57.3 \%$ & 21 & $52.5 \%$ & 22 & $46.8 \%$ & 28 & $65.1 \%$ & 14 & $56.0 \%$ & 58 & $56.9 \%$ & 6 & $46.2 \%$ \\
\hline & & Negative & 19 & 16 & $21.3 \%$ & 3 & $7.5 \%$ & 5 & $10.6 \%$ & 8 & $18.6 \%$ & 6 & $24.0 \%$ & 17 & $16.7 \%$ & 2 & $15.4 \%$ \\
\hline e. Te & Formal & Positive & 104 & 66 & $88.0 \%$ & 38 & $95.0 \%$ & 43 & $91.5 \%$ & 42 & $97.7 \%$ & 19 & $76.0 \%$ & 95 & $93.1 \%$ & 9 & $69.2 \%$ \\
\hline & & Negative & 65 & 45 & $60.0 \%$ & 20 & $50.0 \%$ & 22 & $46.8 \%$ & 25 & $58.1 \%$ & 18 & $72.0 \%$ & 58 & $56.9 \%$ & 7 & $53.8 \%$ \\
\hline & Others & Positive & 61 & 42 & $56.0 \%$ & 19 & $47.5 \%$ & 24 & $51.1 \%$ & 22 & $51.2 \%$ & 15 & $60.0 \%$ & 55 & $53.9 \%$ & 6 & $46.2 \%$ \\
\hline & & Negative & 22 & 18 & $24.0 \%$ & 4 & $10.0 \%$ & 2 & $6.4 \%$ & 7 & $16.3 \%$ & 12 & $48.0 \%$ & 16 & $15.7 \%$ & 6 & $46.2 \%$ \\
\hline & Formal & Positive & 102 & 65 & $86.7 \%$ & 37 & $92.5 \%$ & 43 & $91.5 \%$ & 40 & $93.0 \%$ & 19 & $76.0 \%$ & 91 & $89.2 \%$ & 11 & $84.6 \%$ \\
\hline & & Negative & 22 & 16 & $21.3 \%$ & 6 & $15.0 \%$ & 6 & $12.8 \%$ & 10 & $23.3 \%$ & 6 & $24.0 \%$ & 20 & $19.6 \%$ & 2 & $15.4 \%$ \\
\hline & Others & Positive & 64 & 42 & $56.0 \%$ & 22 & $55.0 \%$ & 24 & $51.1 \%$ & 25 & $58.1 \%$ & 15 & $60.0 \%$ & 57 & $55.9 \%$ & 7 & $53.8 \%$ \\
\hline & & Negative & 14 & 13 & $17.3 \%$ & 1 & $2.5 \%$ & 2 & $4.3 \%$ & 5 & $11.6 \%$ & 7 & $28.0 \%$ & 12 & $11.8 \%$ & 2 & $15.4 \%$ \\
\hline
\end{tabular}

Formal: RM encounters in formal clinical courses

Others: RM encounters in informal situations

a-d: Logistic regression was applied to predict RM encounters by category, context, and type (positive or negative) (independent variable) with gender, age, and admission group as independent variables. Significant variables (italic) in the equations were gender $(a)$ and age $(b, c, d)$

${ }^{\mathrm{a}} \mathrm{R} 2$ (Nagelkerke)0.144, Predicted percentage correct 67.8, Significant variable in the equation (gender, sig. $<0.01, \operatorname{Exp}(\mathrm{B}) 4.266$ )

${ }^{\mathrm{b}} \mathrm{R} 2$ (Nagelkerke) 0.153 , Predicted percentage correct 83.5, Significant variable in the equation (age, sig. $<0.05$, $\operatorname{Exp}(\mathrm{B}) 2.814$ )

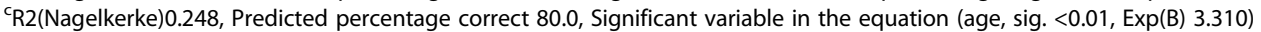

${ }^{d}$ R2(Nagelkerke)0.144, Predicted percentage correct 87.8, Significant variable in the equation (age, sig. $<0.05$, Exp(B) 3.287)

with findings from studies conducted in North American countries; this may be because of cultural differences and social norms, as Japanese medical students tend to accept professional values without being critical, or because for some reason, fewer unprofessional RMs are employed by Kagoshima University. Reddy et al. reported that medical students' perceptions of unprofessional behavior changed during the clinical training period, as they tended to be more accepting of unprofessional behavior after they had completed clinical training [12]. Another explanation could be that general admission students who entered medical school as high school graduates were younger and found it easier to accept new values than medical students in North America, who are more similar to the bachelor students in this study. However, the majority of students in this study still encountered negative RMs, and this suggests that young trainees commonly encounter both positive and negative RMs in the clinical training environment; these encounters therefore appear to be part of the natural process of professional development.

Hafferty and Franks reported that physicians start to develop an identity of self-starting with the student selection process, and that the overall process of medical 
Table 3 Student RM encounters in each category in formal clinical training courses

\begin{tabular}{|c|c|c|c|c|c|c|}
\hline \multirow{3}{*}{$\begin{array}{l}\text { Encountered RMs } \\
\text { Category of behaviors \& attributes }\end{array}$} & \multicolumn{2}{|c|}{ Students' experience } & \multicolumn{4}{|c|}{ Student attributes } \\
\hline & & & \multicolumn{2}{|c|}{ Age (years) } & \multirow{2}{*}{$\begin{array}{l}\text { Gender } \\
\text { Male \% }\end{array}$} & \multirow{2}{*}{$\begin{array}{l}\text { Admission } \\
\text { Bachelor \% }\end{array}$} \\
\hline & Pos/Neg & $n$ & Mean & SD & & \\
\hline \multirow[t]{4}{*}{ a. Relationship with patients } & $P$ & 40 & 26.2 & 4.01 & $62.5 \%$ & $12.5 \%$ \\
\hline & $P+N$ & 62 & 26.4 & 4.66 & $66.1 \%$ & $6.5 \%$ \\
\hline & $\mathrm{N}$ & 11 & 28.0 & 3.80 & $81.8 \%$ & $36.4 \%$ \\
\hline & None & 2 & 24.5 & 0.71 & $0 \%$ & $0 \%$ \\
\hline \multirow[t]{4}{*}{ b. Clinical expertise } & $P$ & 81 & 26.3 & 3.85 & $67.9 \%$ & $12.3 \%$ \\
\hline & $P+N$ & 22 & 27.2 & 6.20 & $59.1 \%$ & $4.5 \%$ \\
\hline & $\mathrm{N}$ & 5 & 26.6 & 3.64 & $100 \%$ & $20.0 \%$ \\
\hline & None & 7 & 25.4 & 3.41 & $28.6 \%$ & $14.3 \%$ \\
\hline \multirow[t]{4}{*}{ c. Humanity, personal attributes } & $P$ & 46 & 25.8 & 3.85 & $60.9 \%$ & $10.9 \%$ \\
\hline & $P+N$ & 54 & 26.6 & 4.62 & $66.7 \%$ & $5.6 \%$ \\
\hline & $\mathrm{N}$ & 11 & 29.1 & 4.76 & $81.8 \%$ & $45.5 \%$ \\
\hline & None & 4 & 24.5 & 0.58 & $50.0 \%$ & $0 \%$ \\
\hline \multirow[t]{4}{*}{ d. Lifestyle } & P & 59 & 26.4 & 4.16 & $69.5 \%$ & $15.3 \%$ \\
\hline & $P+N$ & 25 & 26.7 & 5.88 & $68.0 \%$ & $0 \%$ \\
\hline & $\mathrm{N}$ & 11 & 28.2 & 4.05 & $81.8 \%$ & $36.4 \%$ \\
\hline & None & 20 & 25.2 & 1.99 & $40.0 \%$ & $0 \%$ \\
\hline \multirow[t]{4}{*}{ e. Teaching students and health care professionals } & $P$ & 49 & 25.9 & 3.98 & $59.2 \%$ & $12.2 \%$ \\
\hline & $P+N$ & 55 & 26.5 & 4.54 & $67.3 \%$ & $5.5 \%$ \\
\hline & $\mathrm{N}$ & 10 & 28.8 & 4.57 & $80.0 \%$ & $40.0 \%$ \\
\hline & None & 1 & 24.0 & & $100 \%$ & $0 \%$ \\
\hline \multirow[t]{4}{*}{ f. Contributions to the community } & $P$ & 84 & 26.0 & 3.68 & $63.1 \%$ & $11.9 \%$ \\
\hline & $P+N$ & 18 & 27.6 & 6.72 & $66.7 \%$ & $5.6 \%$ \\
\hline & $\mathrm{N}$ & 4 & 27.5 & 3.51 & $100 \%$ & $25.0 \%$ \\
\hline & None & 9 & 27.7 & 4.30 & $66.7 \%$ & $11.1 \%$ \\
\hline
\end{tabular}

$R M$ role model, SD standard deviation

$\mathrm{P}$ : students who encountered only positive RMs; $\mathrm{P}+\mathrm{N}$ : students who encountered both positive and negative RMs; $\mathrm{N}$ : students who encountered only negative RMs; None: students who did not encounter any RMs

education is important for their moral training [16]. White et al. suggested that students' pre-existing values might intensify, transform, or be compromised based on encounters with positive or negative RMs [21]. Kegan's "self-authorship" schema explains that individuals with a developed sense of self have a "self-authorship" process characterized by being able to self-initiate, self-correct, and self-assess without necessarily having to depend on others to frame problems or articulate necessary adjustments [22].

Most students who encounter negative RMs tend to experience value conflicts [23]. Resolving value conflicts is a challenging process of value negotiations and adjustment, and this varies among students based on their developmental stage.

In this study, students who encountered both positive and negative RMs appeared to gain a greater sense of self-achievement and receive more enjoyment from learning than students who did not. Among the categories and types of RM behaviors, encountering positive RMs in terms of "relationship with patients" and "lifestyle" and both positive and negative RMs in terms of "teaching" significantly increased students' recognition of self-achievement. Therefore, encountering multiple or different types of RMs might facilitate student learning and help them resolve value conflicts. Encountering 


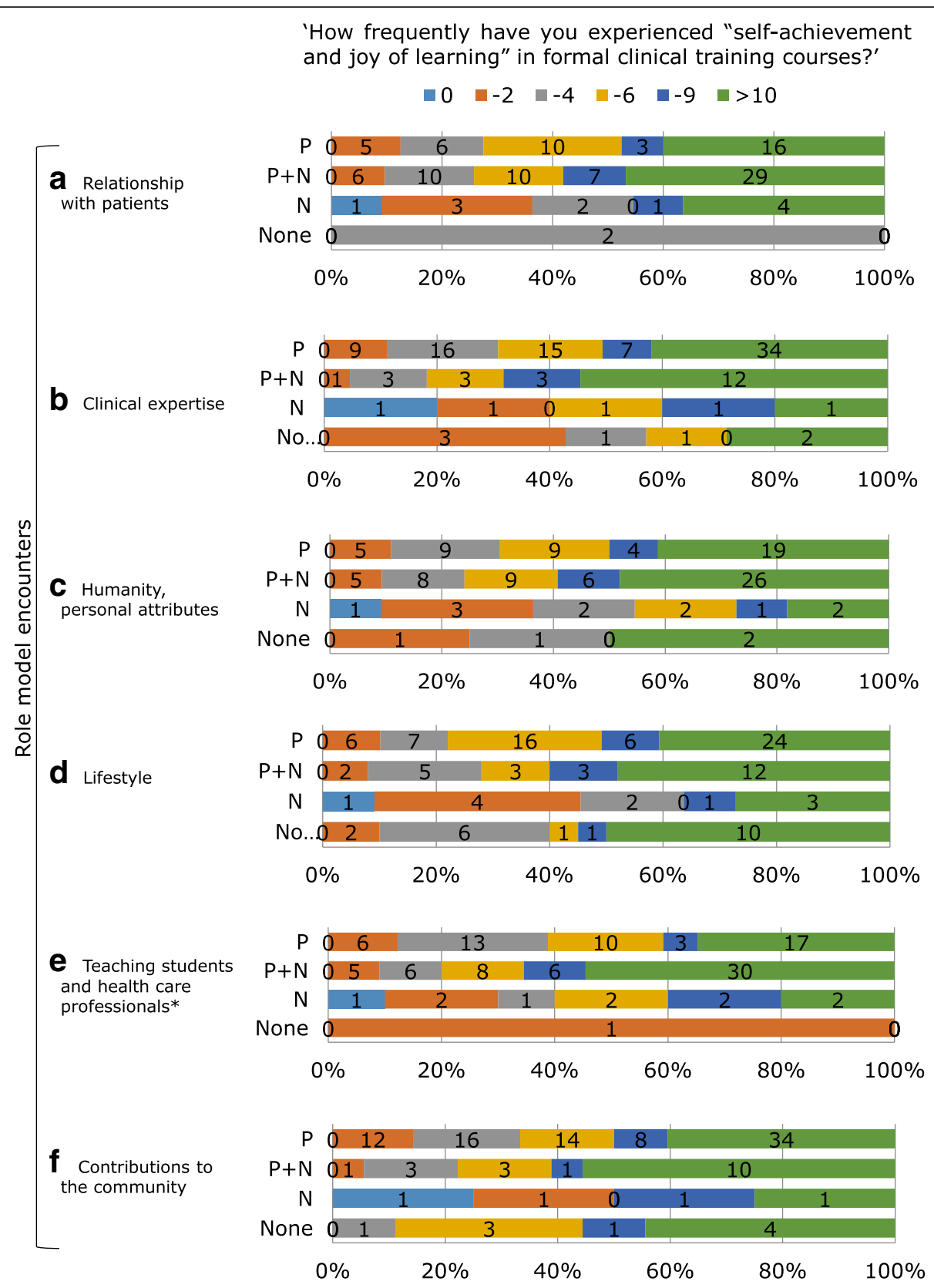

Fig. 2 Student recognition of self-achievement and joy of learning in specific RM encounters (a-f). Students were divided into the following four RM encounter groups: P, students who encountered only positive RMs; P + N, students who encountered both positive and negative RMs; N, students who encountered only negative RMs; and None, students who did not encounter any RMs. Students rated their frequency of recognition of "Self-achievement and joy of learning" on 6-point Likert scale as follows: 1, none; $2,1-2$ times; 3, 3-4 times; 4, 5-6 times; 5, 7-9 times; and 6,10 times or more. The number of students in each scale is indicated by the bars. *The level of significance was set at $p<0.05$ for the Kruskal-Wallis test regarding student distribution on the scale for role model encounter groups $(P, P+N, N$, None)

negative RMs might have favorable effects if students' norms and values are intensified by encountering positive RMs.

Negative RMs were less frequently associated with clinical expertise and contributions to the community. This finding is consistent with those in previous studies on unprofessional behavior, poor doctor-patient relationships, personal attributes, and teaching ability $[9$, 11-13]. White et al. reported that what students learned about patient-centered care during the preclinical years differed from what they actually experienced in their clinical clerkships, and suggested that their values might have been reinforced, compromised, or transformed as a result of this conflict [21]. In Japan, preclinical education 
regarding the patient-centered approach and teamwork may create discrepancies in values between medical students and doctors in relation to communication and interpersonal skills, which have been emphasized since the 1990s.

Students in this study reported encountering more negative RMs in relation to patient relationships and humanity compared with clinical competency, suggesting that "negative" perceptions may develop as an outcome of formal preclinical curriculum that aims to foster patient-centeredness and interpersonal skills, in addition to their values, which may be similar to those of a layperson. Furthermore, RM behaviors and attributes in relation to patient relationships, teaching, and lifestyle were influential categories for student learning, suggesting the importance of these RM behaviors and attributes for students.

A primary mission of Kagoshima University is to foster health professionals who are responsible for community medicine, including remote islands in Kagoshima Prefecture. The formal curriculum for sixth-year medical students includes a clerkship in either the remote islands or a rural area. The majority of students likely responded that they had encountered positive RMs in terms of contributions to the community because the formal curriculum provides students with the opportunity to interact with devoted community health care workers with excellent clinical competency and personalities who demonstrate such qualities. In this case, the curriculum likely increased the chance of encountering positive RMs and the likelihood of positive student perceptions.

In this study, older age and holding a bachelor's degree before admission to medical school appear to have been influential factors in encountering fewer positive and more negative RMs. These students may have established their values prior to starting medical education. Encounters with negative RMs led to maintenance of their own values, as indicated by White in regard to "self-authorship" [21]. This suggests the possibility that older students and bachelor holders may face the challenge of strong value conflict as well as dissatisfaction with instructors and their learning environment. Those students must repeatedly negotiate between their preexisting personal values and socially and professionally required desired values.

Although both male and female students had equivalent opportunities to encounter positive and negative RMs in formal clinical training courses, some gender differences, such as fewer negative RM encounters reported by female students, were identified. About $88 \%$ of the faculty members of the Kagoshima University Faculty of Medicine were male in 2014, and the majority of instructors on clinical rotation were also male. This poses the question of whether female students applied their own personal values to male instructors or recognized male instructors as personal RMs. Furthermore, whether female students tend to accept professional values and compromise their own values more easily than their male counterparts remains unclear. It is also unclear whether RMs behaved better in front of female students. Stratton et al. reported that both male and female thirdyear medical students in a southeastern US medical school assigned roughly the same overall ranking to unprofessional behaviors of medical students, residents, and attending physicians [24]. Gude et al. reported that, compared with their male counterparts, female students had trouble identifying themselves as doctors, and therefore proposed that female students need to have female RMs [25]. The presence of gender differences in role modeling and professional development, perceptions of negative behavior or attributes, and value modification through interactions with RMs, need to be investigated in future studies, in addition to the lack of female RMs and the attributes of female students in medical education [26].

Medical educators need to consider the diversity among medical students, such as prior personal experiences and their resulting developmental statuses and values, and to facilitate conflict resolution compatible for individual levels of personal and professional development, even if they have same ethnic background and learn the same formal curriculum.

This study did have several limitations. First, the study sample only included one university in Japan, and the response rate was low; therefore, some care should be taken when generalizing the results. Second, data were based on student memories, and only one item was used for recognition of self-achievement, and therefore may not be reliable. Third, the RM categories and clinical situations used in this study were preset, and therefore may not cover the full range of RMs and situations. Further research is needed to confirm whether the differences and influential factors revealed in this research are applicable to other ethnicity groups, curriculums, and stages of medical education.

\section{Conclusions}

Even if students have the same ethnic background and are learning the same curriculum, male students had more negative perceptions about their RMs compared with their female counterparts. In addition, older and more experienced students reported encountering more negative RMs, especially in terms of teaching-related behaviors.

Although most medical students encounter both positive and negative RMs during undergraduate medical education, the findings from this study suggest that in a variety of aspects, especially in terms of RM behaviors 
and attributes related to patient relationships, lifestyle, and teaching, encountering not only positive RMs, but also negative RMs, might facilitate student learning.

\section{Additional file}

Additional file 1: Self-administered questionnaire regarding medical students' role model encounters. (DOC $49 \mathrm{~kb}$ )

\section{Abbreviation}

$\mathrm{RM}$, role model

\section{Acknowledgments}

The author gratefully acknowledges all participants who took part in this research and specifically Kyoko Mineyama for her excellent work in data gathering.

\section{Funding}

This work was supported by JSPS KAKENHI (Grant Number 24590620).

\section{Availability of data and materials}

All data are stored according to agreements with participants and ethical standards.

\section{Authors' contribution}

MT designed the study, performed the statistical analyses, and drafted, edited, and approved the final manuscript to be submitted.

\section{Authors' information}

MT is MD. PhD. MHPE and Director and Professor of the Center for Innovation in Medical and Dental Education, Graduate School of Medical and Dental Sciences, Kagoshima University, 8-35-1 Sakuragaoka, Kagoshima 890-8544, Japan.

\section{Competing interests}

The author declares that she has no competing interests.

\section{Consent for publication}

Written informed consent to participate the research and to publish anonymous data was obtained from all participants.

\section{Ethics approval and consent to participate}

The research project was ethically approved by Graduate School of Medical and Dental Sciences, Kagoshima University (No.257).

Received: 25 April 2015 Accepted: 14 June 2016

Published online: 23 June 2016

\section{References}

1. Kenny NP, Mann KV, MacLeod H. Role modeling in physicians' professional formation: reconsidering an essential but untapped educational strategy. Acad Med. 2003:78:1203-10.

2. Cruess SR, Cruess RL, Steinert Y. Role modelling-making the most of a powerful teaching strategy. BMJ. 2008;336:718-21.

3. Wright S, Wong A, Newill C. The impact of role models on medical students. J Gen Intern Med. 1997;12:53-6.

4. Curry SE, Cortland Cl, Grham MJ. Role-modelling in the operating room: medical students observations of exemplary behaviour. Med Educ. 2011 ; 45:946-57

5. Wright SM. Examining what residents look for in their role models. Acad Med. 1996:71:290-2.

6. Wright SM, Kern DE, Kolodner K, Howard DM, Brancati F. Attributes of excellent attending-physician role models. N Engl J Med. 1998:339:1986-93.

7. Cote L, Leclere $H$. Clinical teachers perceive the doctor-patient relationship and themselves as role models. Acad Med. 2000:75:1117-24.

8. Passi V, Johnson S, Peile E, Wright S, Hafferty F, Johnson N. Doctor role modelling in medical education: BEME Guide No. 27. Med Teach. 2013:35: e1422-36
9. Feudtner C, Christakis DA, Christakis NA. Do clinical clerks suffer ethical erosion? Students' perceptions of their ethical environment and personal development. Acad Med. 1994;69:670-9.

10. Satterwhite WM, Satterwhite RC, Enarson CE. Medical students' perceptions of unethical conduct at one medical school. Acad Med. 1998;73:529-31.

11. Ginsburg S, Regehr G, Stern D, Lingard L. The anatomy of the professional lapse: bridging the gap between traditional frameworks and students' perceptions. Acad Med. 2002;77:516-22.

12. Reddy ST, Farnan JM, Yoon JD, Leo T, Upadhyay GA, Humphrey HJ, Arora VM. Third-year medical students' participation in and perception of unprofessional behaviors. Acad Med. 2007:82:S35-9.

13. Baldwin DC, Daugherty SR, Rowley BD. Unethical and unprofessional conduct observed by residents during their first year of training. Acad Med. 1998;73:1195-200.

14. Swick HM. Professionalism and humanism beyond the academic health center. Acad Med. 2007:82:1022-8.

15. Wolf TM, Balson PM, Faucett JM, Randall HM. A retrospective study of attitude change during medical education. Med Educ. 1989;23:19-23.

16. Hafferty FW, Franks R. The hidden curriculum, ethics teaching, and the structure of medial eduation. Acad Med. 1994:69:861-71.

17. Stern DT. In search of the informal curriculum: when and where professional values are taught. Acad Med. 1998;10:S28-30.

18. Stern DT. Practicing what we preach? An analysis of the curriculum of values in medical education. Am J Med. 1998;104:569-75.

19. Shuval JT, Adler I. The role of models in professional socialization. Soc Sci Med. 1980;14A:5-14.

20. Kruskal WH, Wallis WA. Use of ranks in one-criterion variance analysis. J Am Stat Assoc. 1952;47:583-621. Addendum. 1953:48:907-911.

21. White CB, Kumagai AK, Ross PT, Fantone JC. A qualitative exploration of how the conflict between the formal and informal curriculum influences student values and behaviors. Acad Med. 2009:84:597-603.

22. Kegan R. In over our heads: the mental demands of modern life. Cambridge: Harvard University Press; 1994.

23. Ginsburg S, Regehr G, Hatala R, McNaughton N, Frohna A, Hodges B, Lingard L, Stern D. Context, conflict, and resolution: a new conceptual framework for evaluating professionalism. Acad Med. 2000;75:56-11.

24. Stratton TD, Conigliaro RL. Does gender moderate medical students' assessments of unprofessional behavior? J Gen Intern Med. 2012;27:1643-8.

25. Gude T, Vaglum P, Tyssen R, Ekeberg O, Hem E, Røvik JO, Finset $K_{\text {, }}$ Gronvold NT. Identification with the role of doctor at the end of medical school: a nationwide longitudinal study. Med Educ. 2005;39:66-74.

26. Clack GB, Head JO. Gender differences in medical graduates' assessment of their personal attributes. Med Educ. 1999:33:101-5.

\section{Submit your next manuscript to BioMed Central} and we will help you at every step:

- We accept pre-submission inquiries

- Our selector tool helps you to find the most relevant journal

- We provide round the clock customer support

- Convenient online submission

- Thorough peer review

- Inclusion in PubMed and all major indexing services

- Maximum visibility for your research

Submit your manuscript at www.biomedcentral.com/submit 